\title{
Development of matte finishes in electrostatic (EFB) and conventional hot dipping (CHDFB) fluidized bed coating process
}

\author{
M. Barletta ${ }^{\text {a,* }}$, G. Bolelli ${ }^{b}$, S. Guarino ${ }^{\text {a }}$, L. Lusvarghi ${ }^{b}$ \\ a Università degli Studi di Roma 'Tor Vergata', Dipartimento di Ingegneria Meccanica, Via del Politecnico, 1, 00133 Roma, Italy \\ ${ }^{\mathrm{b}}$ Università degli Studi di Modena e Reggio Emilia, Dipartimento di Ingegneria dei Materiali e dell'Ambiente, \\ Via Vignolese, 905-41100 Modena, Italy \\ Received 17 July 2006; accepted 16 January 2007
}

\begin{abstract}
This study focuses on the correlation between the thermo-rheological properties of a thermosetting powder coating system with its surface structure build-up. Epoxy powder coating systems, which displayed surface matting and surface wrinkling, were examined. Firstly, the evolution of the complex viscosity was correlated with the cure kinetic. Secondly, the structure build-up on the surface of the coatings was investigated with a combined SEM-CLA profilometry analysis at different stages of curing process for both EFB and CHDFB coating processes. Different finishes were found to characterize the films applied by using EFB and CHDFB coating processes as a result of the different way the film is heated by. Finally, a strict relationship of film morphology to the degree of conversion and to the evolution of the complex viscosity was found out for both EFB and CHDFB coating processes. The surface structure is built up after gelation point and continues to evolve after gelation with a full development of the film fine structure. Differences were observed in the surface structure build-up when different curing temperature was used, thereby indicating an influence of minimum viscosity on achievable finishing.

These experimental results lead to further advances in a better understanding of the formation of surface topography and morphology of polymeric films. They also provide important indications for the settings of curing parameters in both EFB and CHDFB coating processes as well as for the development of new powder coating formulations.
\end{abstract}

(C) 2007 Elsevier B.V. All rights reserved.

Keywords: Powder coatings; Fluidized bed; Film morphology

\section{Introduction}

\subsection{Premise and historical background}

In electrostatic (EFB) and conventional hot dipping (CHDFB) fluidized bed coating process, an understanding of the stages by which a deposited powder is converted to a fully consolidated film requires the investigation of several properties such as substrate roughness, surface tension, thermo-rheological behaviour, curing kinetic of the resin and the operational parameters during coating process. Film properties like modulus, adhesion, impact, scratch and wear endurance, residual stresses distribution, chemical resistance to aggressive agents as salt fogs, acid or alkaline environment, physical characteristics and, above all, appearance are strictly dependent upon operational

\footnotetext{
* Corresponding author. Tel.: +39 0672597168; fax: +39 062021351.

E-mail address: barletta@mail.mec.uniroma2.it (M. Barletta).
}

choices in deposition and curing phases, in preparation of substrates surface and, mostly, upon chemical composition of the resin, curing agents and additives.

Several studies have attempted to correlate the film appearance to the operational settings of fluidized bed coating processes. Since 1962, Richart and Pettigrew tried to find a correlation between surface appearance and part location and vibration, preheating temperature and coating time in a CHDFB coating process [1-4]. In 1977, Strucaly started studying correlation between electrostatic parameters (voltage and current intensity) and surface appearance in EFB coating process of armatures for electric motors [5]. In nineties, Leong et al. developed experimental and numerical studies about correlation among film properties and substrate materials and geometries in CHDFB coating process [6]. Inculet and co-workers modelled the relationship between part shape and film uniformity in both electrostatic and tribo-charged fluidized bed [7,8]. More recently, Barletta et al. built first approximation models describing the trend of average roughness of polymeric film deposited 
by EFB $[9,10]$ and CHDFB $[11,12]$ by varying the deposition conditions. First time, they also attempted to model the evolution from the status of loose powders to the status of consolidated film, which a thermoplastic polymeric film run through [12], hence individuating three different phases: powder melting, levelling and formation of a continuous smooth film.

On the other hand, since 1976, Hannon et al. [13] understood the correlation between surface appearance and the rheological characteristics of the coatings, suggesting that the complex viscosity, $\eta^{*}$, might be a useful measure of the progress of two important aspects of the coating process. They found out that $\eta^{*}$, at the early stages of cure, measured the viscosity which, together with the surface tension, determined the surface appearance and, in the later stages, $\eta^{*}$ was a measure of the modulus, which in turn measured the degree of crosslinking of the resin and its mechanical properties. During the following years, scientific world attention was moved on definition of new powder paint formulations based upon polymeric blends, which were expected to provide diverse coating texture such as low gloss (i.e. matte finishes with gloss <5\%), high clarity for automotive topcoats, high abrasion resistance and polychromatic or gonioapparent effects $[14,15]$. Accordingly, the influence of new resin additives like curing agents, flow promoters and extenders onto final film morphology was also widely discussed [16-18]. However, most publications have been mainly concerned only with the levelling of powder coatings and not with the development of matte finishes [19-21]. In fact, few attempts have so far been made to correlate the thermal and rheological behaviour of powder coatings with their surface structure build-up during curing. In general, surface appearance has always been described only by gloss and colour of the surface as well as by surface roughness trends according to settings of coating process [22] and no correlations between film morphology and thermo-rheological properties of the resins were sought.

In this context, Lee et al. were the first to study, at relatively high resolution, the surface structure build-up during curing and to establish a correlation between the microscopic surface structure and the thermal and rheological properties of the thermosetting powder coatings during curing applied by electrostatic spray deposition [23]. However, the factors generating the surface structure, especially matte and wrinkled surfaces, have not yet been investigated in detail. Furthermore, the correlation between gelation point and coarse and fine structure formation, the influence of minimum viscosity on final film morphology, the relationship between the evolution of surface morphology and the evolution of cure kinetic and viscosity are important issues, which still remain mostly unresolved.

\subsection{The aim of the work}

This study deals with the analysis of relationships between the thermal and rheological behaviour of thermosetting powder coatings and the surface structure build-up during curing in EFB and CHDFB coating process. In particular, the evolution of film morphology versus curing time and temperature in EFB and versus preheating temperature in CHDFB has been the main issue of the led experimental investigation. Deposition conditions of powder coatings by EFB and CHDFB process have followed the indications provided by several past studies which one of the authors developed [9-12]. This way, the influence of coating process parameters on starting characteristics of the deposited films has been minimized.

This is the context in which the present study moves to build the groundwork for a better understanding of the evolution of polymeric film surface appearance and its relationship with thermosetting powder coatings cure kinetics and complex viscosity. For this purpose, the thermo-rheological behaviour of the resin has been studied by a combined analysis between differential scanning calorimetry (DSC) and a torsional parallel-plate rheometer. The surface roughness and structural pattern of film morphology have been investigated, at different stage of the coating process, using a combined analysis of a field emission gun scanning electron microscope and a non-contact profilometry based upon a chromatic aberration lens.

The aim of this study is thus, manifold: (i) to follow at high resolution the evolution of film surface structure during curing at different stages for both EFB and CHDFB coating process, (ii) to document the necking phenomena between powder grains which leads the polymeric coating from a status of loose powder to a status of a full consolidated film, (iii) to interpret the difference in mechanisms which leads to different finishes for EFB- and CHDFB-coated substrates, (iv) to establish a correlation between microscopic surface structure and the thermal and rheological properties of the thermosetting powder coatings during curing for EFB and CHDFB coating processes, and, finally, (v) to single out the influence on final film appearance (development of coarse and fine structure) of degree of conversion, minimum viscosity and gelation point of the resin.

\section{Experimental}

\subsection{Materials}

A commercial epoxy-based thermosetting powder $(20 \mu \mathrm{m}$ as mean diameter of the granulometric distribution, 0.80 as factor shape) supplied by Becker Powder Coatings was employed during experimental tests. The formulation was based upon bisphenol-A type epoxy. Cross-linkers and other additives such as a flowing agent (silica and aluminium oxides), flowing promoter after melting and UV stabilizer (titanium oxides) completed the formulation. Such powder was specifically developed for fluidized bed coating process. It was a low-gloss powder coating, representative of matte powder coating systems used in the industrial, decorative and maintenance industries.

\subsection{Cure kinetics}

Cure kinetic studies were performed using a Differential Scanning Calorimeter (DSC Netzsch model DSC200PC). First, 
dynamic scans $\left(10^{\circ} \mathrm{C} / \mathrm{min}\right.$ from 20 to $\left.250^{\circ} \mathrm{C}\right)$ were carried out to evaluate the overall heat of cure as well as the onset, the endset and the peak point of the curing process. Then, isothermal experiments were carried out at 125,150 , and $175^{\circ} \mathrm{C}$. After the completion of each isothermal run, the sample was cooled rapidly and then scanned at $10{ }^{\circ} \mathrm{C} / \mathrm{min}$ from 20 to $250^{\circ} \mathrm{C}$ in order to determine the residual heat of reaction. The sum of the isothermal heat and the residual heat was taken to represent the ultimate heat of cure. The experimental data measured during reaction were then expressed in terms of conversion degree as a function of time.

\subsection{Rheological behaviour}

A torsional parallel-plate rheometer (Haake model RC9000 Torque Rheometer) was used to evaluate the rheological changes occurring during the curing reaction. The complex viscosity was monitored at isothermal conditions and at a frequency of $10 \mathrm{~Hz}$. The rheometer was stabilized to $100^{\circ} \mathrm{C}$ and then the sample was placed between the parallel plates and heated rapidly to the following isothermal conditions: 125,150 , and $175^{\circ} \mathrm{C}$. The minimum complex viscosity, the rate of viscosity increase and the induction time (the starting time of dramatic increase in viscosity), were accounted for.

\subsection{Substrate preparation}

In order to eliminate any effects of starting surface morphology on the final appearance of the coating [24], the powder paints were applied onto built ad hoc samples. The samples consisted of aluminium slabs $60 \mathrm{~mm} \times 40 \mathrm{~mm} \times 4 \mathrm{~mm}$, which were first machined by high speed milling, than ground to the desired dimensions and, finally, hand-polished by special stones to reach for very uniform average roughness values close to $0.01 \mu \mathrm{m}$. To produce a high electrical conductive surface, a very thin and uniform film $(0.6-0.7 \mu \mathrm{m})$ of a Nickel-Copper alloy was PVD deposited by using a magnetron-sputtering source (Ionvac model MS-PVD). Prior to powder coatings, the substrate was ultrasonically cleaned for $15 \mathrm{~min}$ in ethanol (Soltec model Sonica 2200MH 3lt) and, then, accurately wiped by using a drying chamber at $40{ }^{\circ} \mathrm{C}$ for, at least, $4 \mathrm{~h}$. Afterwards, the samples were coated by using two different techniques: electrostatic (EFB) and conventional hot dipping fluidized bed (CHDFB).

\subsection{Fluidized bed}

A cylindrical fluidized bed (tank), $250 \mathrm{~mm}$ as diameter and $200 \mathrm{~mm}$ as static bed height, of epoxy-based powders, working in fast regime (up to $15 \mathrm{~m}^{3} / \mathrm{h}$ as flow rate), was used for coating purpose (Fig. 1). A thorough description of the experimental apparatus can be found in several previous papers [9-11]. However, it is worth remarking that the column was made from Plexiglas, $4 \mathrm{~mm}$ in thickness to provide enough wall rigidity. A sliding vane rotary compressor Mapro, model 'Free-Oil 20', for flow rates from 3 to $20 \mathrm{~m}^{3} / \mathrm{h}$, pressures up to 0.9 bar relative and $1.5 \mathrm{~kW}$ as maximum power, was used to feed purified air flux lacking in oil and moisture into the fluidized bed, under strictly monitored process conditions. In fact, a standard flowmeter with a $0-10 \mathrm{~V}$ output a digital control system and an inverter Mitsubishi model FR-S 540E were respectively used to read and control the current value of air flux, hence keeping the flow rate constant during the whole treatment. A set of pressure probes, a hygrometer and a set of thermocouples were also used to monitor the process and environmental conditions. When enough air flux was fed from the blower to the fluidization column, the epoxy powders became individually suspended in the air flow, while on the whole the bed of powder remained motionless relative to the column walls [25]. As the velocity of the gas flowing across the bed was slowly raised, the heterogeneous

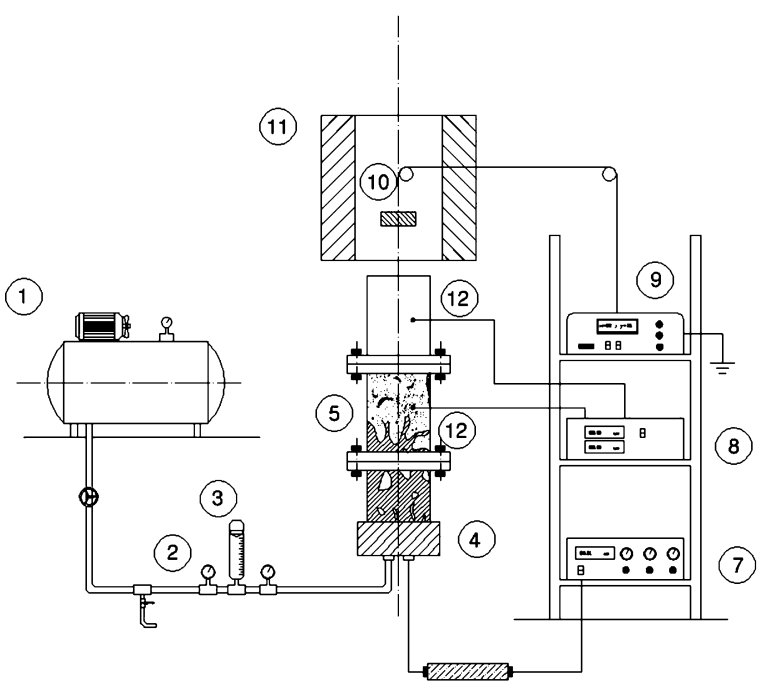

(6)
(1) Air

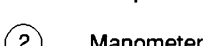

(3) Flow rate meter

(4) Air Plenum Chamber

(5) Tank

(6) Transformer

(7) Voltage controller

(8) Data acquisition unit

(9) Movement system

(10) Specimen

Oven for Substrate Pre-Heating

(12) Monitoring Probes

Fig. 1. Fluidized bed system for EFB and CHDFB coating processes. 
character of the bed first reached its peak and then gradually changed. As the transport velocity was approached, a sharp increase of powder carry-over occurred [25]. The dust collection and solid recycle system of the bed avoided the dispersion into the environment of elutriated powders, and, in this way, it was possible to maintain in the fluidization column a relatively large solid concentration typical of the fast fluidized bed condition, very useful for both $\mathrm{CHDFB}$ and $\mathrm{EFB}$ coating process [9-11].

\subsection{Coating preparation}

In EFB coating process, the fluid bed has been endowed of a set of electrode incorporated in the air plenum chamber or in the porous plate, even if alternative solutions are admissible. The corona charging method, which makes use of a high voltage generator $(0-100 \mathrm{kV})$, has been employed in order to bring an electrostatic charge (mostly negative) onto the powder particles through the intermediate process of creating oxygen ions. For coating purposes, a grounded substrate is dip inside the tank, where a certain volume of the epoxy-based powders is fluidized by ionized air from below. The resulting electrically charged cloud of powder with the help of the transport air moves in the direction of the grounded substrate. As the charged particles come close to the substrate, electrostatic force causes the particles to deposit and adhere on the substrate when it is passed into or through the powder cloud or just hung in it. Varying part location, coating time, electric parameters and hydrodynamic settings, film with different characteristics in terms of thickness, uniformity and appearance can be easily achieved $[9,10]$. With this system, substrate preheating is not necessary. Small amount of powder upon the fluidization plate is necessary and the less dense powder suspension permits an accurate control of film thickness and appearance. This system also eliminates the need for a full dipping of the substrates inside the tank, because powder rises to the substrate. Since substrate is not preheated before being coated, powder can be readily removed from areas, which are to be left bare eliminating the need for mechanical masking and all the problems associated with it.

In CHDFB coating process, the fluidized bed acts like a sort of container for dip painting. In fact, the substrate is first preheated at temperatures in the range of $200-400^{\circ} \mathrm{C}$ in a convective oven (Nabertherm, model B170 30-2000 ${ }^{\circ} \mathrm{C}$ ) and, then, fed to the fluidization column. Here, the substrate is submitted to repeated strikes from polymeric powders taken in a fluid-like state inside the tank by feeding air at moderate pressure (100-150 mbar). Impinging onto the hot substrate surface the powder melts, thereby coating the metal substrate. By varying preheating temperature, coating time, part location in the tank and hydrodynamic condition of the fluidized bed, films with different characteristics in terms of thickness, uniformity and appearance can be attained [11].

However, a full description of both coating techniques with best strategies to set operational parameters can be found in several previous papers [9-11]. Here, it is worth remark- ing that, in both processes, all the coating parameters were accurately controlled to avoid any anomalies or disturbances, which could influence the final appearance of the epoxy coatings and the coating thickness. In particular, to eliminate any influence on led analyses of the coating thickness, EFB and CHDFB deposition processes were controlled to attain values as close as possible to $70 \mu \mathrm{m}$. All the samples, which failed to agree within this specification more than $\pm 5 \%$ were discarded.

\subsection{Curing process}

After the completion of the deposition process in EFB, the coated samples were cured in a convective oven (Naddeo model RT11) at different isothermal conditions (from 110 to $230^{\circ} \mathrm{C}$ ) for various times (from 1 to $120 \mathrm{~min}$ ) to obtain the desired surface changes. To the contrary, no curing process or re-heating was required after $\mathrm{CHDFB}$ process, since the samples were already preheated at prescribed temperatures (from 200 to $400^{\circ} \mathrm{C}$ ) before being dipped in the fluidized powders. The preheating should be enough to cause the powders to adhere on the sample surface as well as to melt and consolidate them in a form of a continuous film.

\subsection{Residual degrees of conversion}

Residual degrees of conversion were estimated onto EFBcoated samples after curing process. For such purpose, some material (at least $20 \mathrm{mg}$ ) was taken from the surface of each substrate and, then, submitted to a dynamic scan at $10^{\circ} \mathrm{C} / \mathrm{min}$ from 20 to $250{ }^{\circ} \mathrm{C}$ by using DSC Netzsch. The ratio of the residual heat of reaction measured on cured samples to the overall heat of reaction measured on the virgin powders as explained in Section 2.2 was taken as an estimation of the residual degree of conversion.

\subsection{Surface topography and roughness measurements}

Images of film morphologies were obtained using a Field Emission Gun Scanning Electron Microscope (FEG-SEM Leo model Supra 35) using the in-lens detector. The threedimensional morphology of the coatings was obtained with a Taylor Hobson Surface Topography System (model TalySurf CLI 2000) using the non-contact $300 \mu \mathrm{m}$ chromatic aberration length (CLA) HE gauge.

In comparison to conventional system, the CLA HE gauge offers superior imaging capability with improved resolution $(10 \mathrm{~nm}$ and $0.4 \mu \mathrm{m}$ as vertical and lateral resolution, respectively). Scanning in three dimensions can be performed and the absence of contact between the gauge and the surface being measured ensures the avoidance of any damages or alterations to the surface being measured.

For the CLA profilometry, the samples were located under the gauge and viewed optically, using the high-resolution camera built into the surface topography system. This enabled the choice of the measurement area and the rough focusing of the gauge. Using the CLA HE scanning mode, a number of patterns 
(1000), each $4 \mathrm{~mm}$ long, were recorded for each sample so as to cover a representative area $\left(16 \mathrm{~mm}^{2}\right)$ of the entire surface structure. The surface morphology was then examined by using the TalyMap software release 4.0. As a characteristic of the coatings morphology, amplitude, spacing and hybrid parameters for both waviness and roughness profiles (standard Gaussian filter) were considered.

\section{Results and discussion}

\subsection{Cure kinetics}

Cure kinetic of the epoxy-based powders has been studied by thermal analysis [26]. This way, an empirical model, based on the experimental results coming from DSC tests, which correlates conversion with curing time and temperature has been built.

DSC signals are reported as a function of time in Fig. 2 for three isothermal runs together with the full dynamic scan. Being the cure reaction of epoxy systems auto-catalyzed, a simplified autocatalytic model $[27,28]$ can be applied to describe the cure kinetics of our powders:

$\frac{\mathrm{d} \alpha}{\mathrm{d} t}=\kappa_{1} \alpha^{\mathrm{m}}(1-\alpha)^{\mathrm{n}}$

$\kappa_{1}=\kappa_{10} \exp \left(\frac{-E_{1}}{R T}\right)$

where $\alpha$ is the degree of conversion; $k_{1}$ the reaction rate constants with its activation energy $E_{1}$ and pre-exponential factor $k_{10} ; m$ and $n$ are the reaction orders with $(m+n)$ accounting for the overall reaction order.

Fig. 3 reports the reaction rate constant $k_{1}$ as an Arrhenius plot, where $R$ is the gas constant, $T$ the temperature expressed in $\mathrm{K}$ and $t$ the curing time. Activation energy and all the kinetic parameters $k_{1}, m$ and $n$ of the proposed model were determined using Marquardt's multivariable non-linear regression method [29]. An activation energy of about $50 \mathrm{~kJ} / \mathrm{mol}$ was calculated. However, the results are stored in Table 1. Values of the kinetic parameters very close to those reported in the

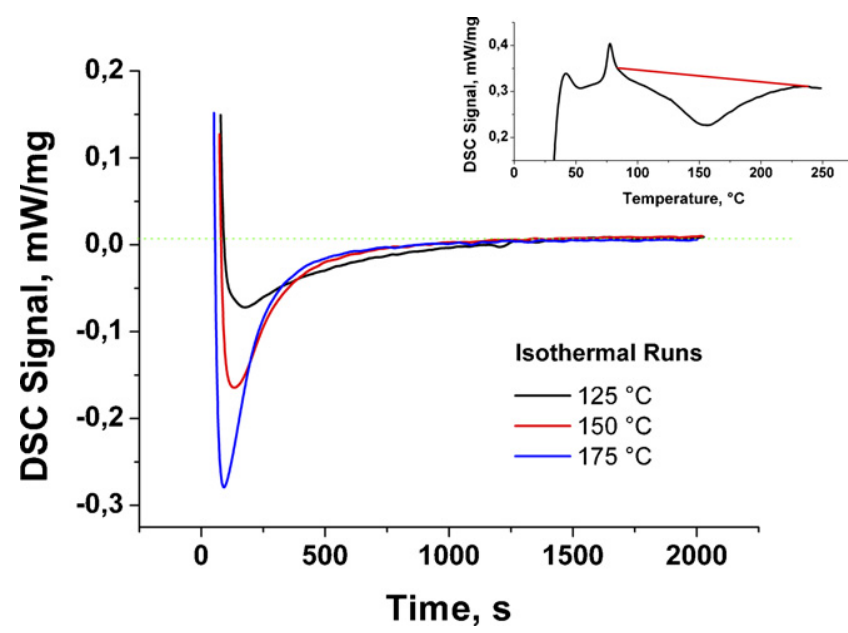

Fig. 2. Isothermal and dynamic DSC runs of the epoxy-based system.

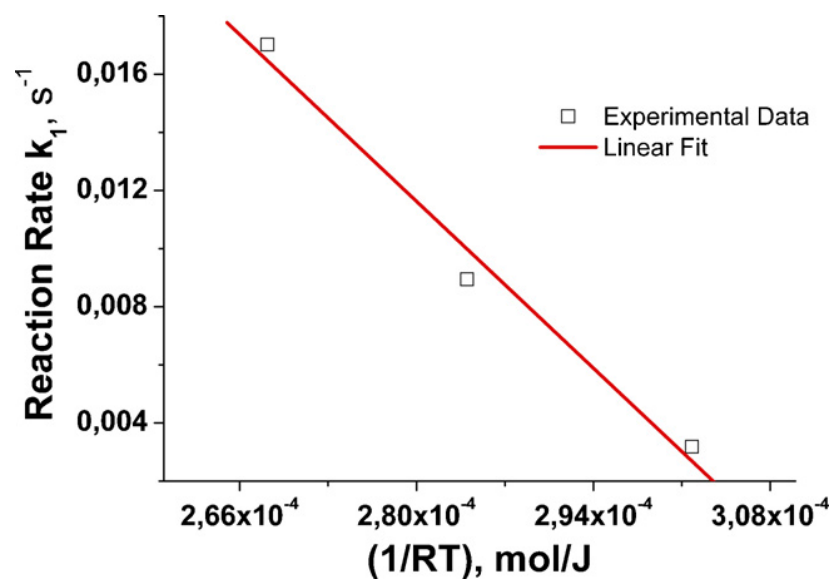

Fig. 3. Arrhenius type trend of the kinetic constant for the epoxy-based system.

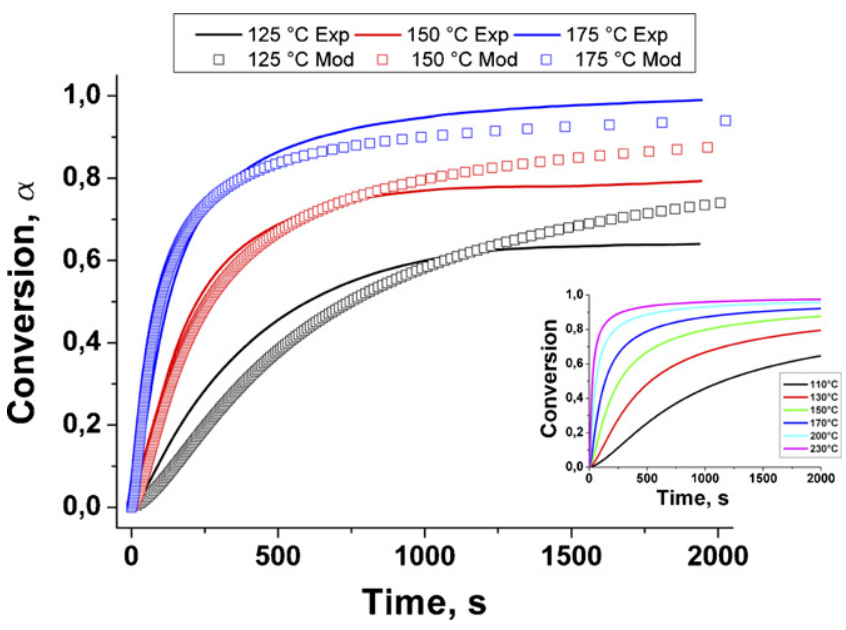

Fig. 4. DSC experimental and numerical degrees of conversion of the epoxybased system.

literature for hybrid epoxy-based powder paints were found $[23,26]$.

A comparison between the experimentally obtained degree of conversion and the predictions of the empirical model, using the values of the kinetic parameters summarized in Table 1, is displayed in Fig. 4. Even if some differences between experimental and numerical data arose, the model is able to catch well the trends of the first part of conversion curves for 150 and $175^{\circ} \mathrm{C}$ (that is, the first part of curing process where faster conversion variations take place) and, above all, to discriminate among the different curing time where the three conversion curves bend to approach their respective asymptotic values of conversion. More sophisticated models could significantly improve the over-

Table 1

Curing and kinetic parameters of the epoxy-based system $\left(R^{2}\right.$ of 0.951$)$

\begin{tabular}{lclc}
\hline Dynamic scan, thermal properties & \multicolumn{3}{l}{ Isothermal runs, kinetic parameters } \\
\hline$T_{\text {onset }}(\mathrm{K})$ & 356 & $k_{10}\left(\mathrm{~s}^{-1}\right)$ & 11849 \\
$T_{\text {endset }}(\mathrm{K})$ & 409 & $E_{1}(\mathrm{~kJ} / \mathrm{mol})$ & 49.985 \\
$T_{\text {peak }}(\mathrm{K})$ & 428 & $m$ & 0.38 \\
Curing heat $(\mathrm{J} / \mathrm{g})$ & 44.89 & $n$ & 2.46 \\
\hline
\end{tabular}




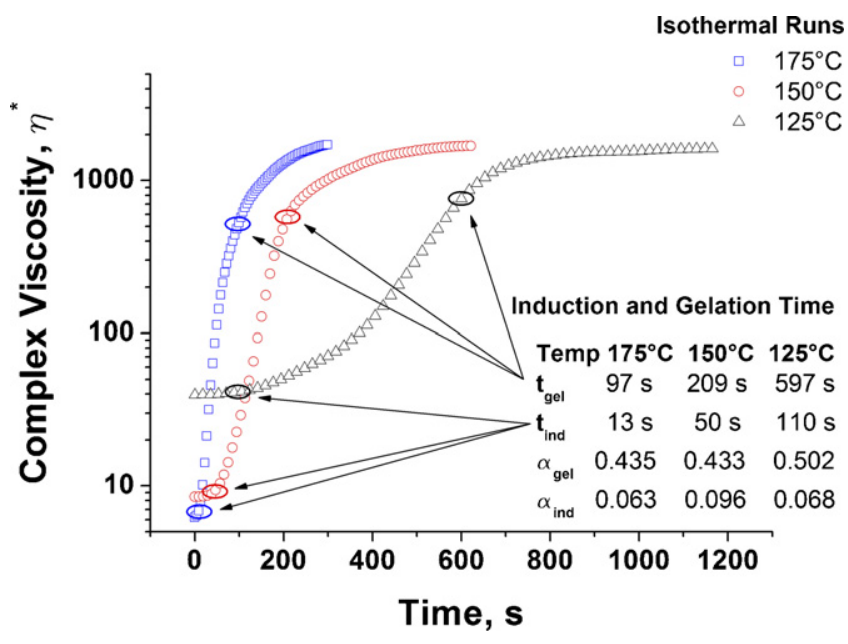

Fig. 5. Complex viscosity of the epoxy-based system.

all fitting of experimental data, yet introducing more empirical parameters and more kinetic terms very difficult to physically interpret.

The kinetic parameters determined from Eq. (1) and DSC experiments are very useful to provide indications to predict the cure behaviour of low curing EP powders. This way, a full map of the degree of conversion according to curing time and temperature was calculated from Eq. (1) and full data are reported in the sketch in Fig. 4.

\subsection{Complex viscosity evolution}

Complex viscosity of the epoxy-based powder paints has been studied by rheological analysis. From three isothermal runs, the evolution of complex viscosity according to curing time and temperature was deducted. The experimental results are displayed in Fig. 5, where, the induction time (i.e. the starting time of the dramatic increase in viscosity [30]) $t_{\text {ind }}$ and the gelation time (i.e. the time when the storage modulus and the loss modulus, of the resin were equal $[23,30]) t_{\text {gel }}$ are reported and the minimum viscosity values and the rate of viscosity increase can be easily calculated.

From experimental data, it can be deducted: (i) the minimum viscosity value decreases with increasing temperature; (ii) after an induction time which decreases by increasing temperature, the viscosity increases dramatically; (iii) once elapsed the induction time, the rate of the viscosity increase depends on the temperature; (iv) a strictly increasing trend of the viscosity occurs during curing; (v) an Arrhenius-type relationship between gelation time and temperature exists (Fig. 6).

Such results fit well with experimental findings reported in the literature, even if Eley [31] earlier and Lee et al. [23] later found a viscosity drop for hybrid epoxy-polyester systems in the time range between the induction and gelation time. Such viscosity drop was ascribed to phase separation during curing [31] or to a loss of homogeneity of the epoxy system due to crosslinking density inhomogeneity related to characteristic reactions [23]. This phenomenon was not detected during our experimen-

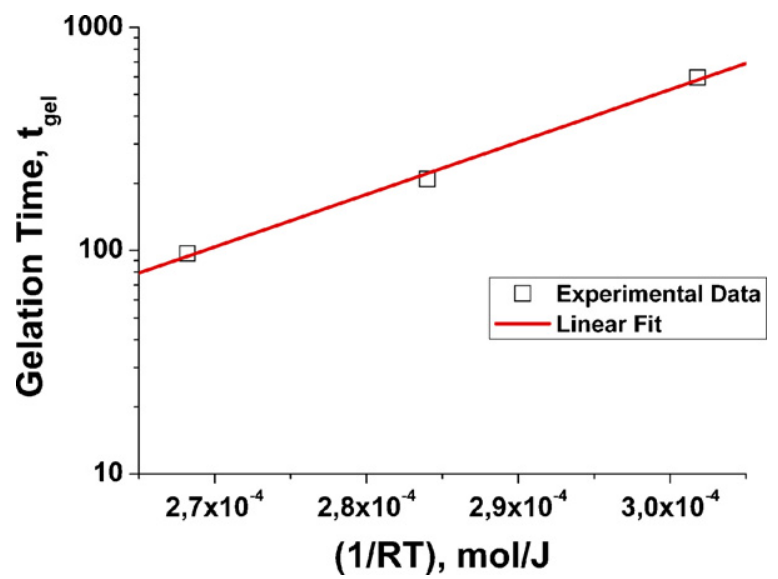

Fig. 6. Arrhenius type trend of the gelation point for the epoxy-based system.

tal tests, where, as said, strictly increasing trends of the viscosity with time occurred.

By joining experimental data from DSC and rheometer, a correlation between viscosity evolution and cure kinetics can be found. Data tabled in Fig. 5 show that induction time always occurs at a degree of conversion lower than 0.1 , while, resin gelation occurs at a degree of conversion in the range of $0.4-0.5$. The correlation between complex viscosity data and degree of conversion for our epoxy system reflects very well data reported in the literature for similar materials (hybrid epoxy-polyester systems) and for other polymeric materials (polyurethane systems) [23].

\subsection{Determination of residual heat of conversion of cured film onto EFB- and CHDFB-coated substrates}

In Section 3.1 of this work, the kinetic behaviour of the epoxy-based system has been studied by using standard condition and a differential scanning calorimeter. A correlation model between degree of conversion and curing time and temperature has been proposed. Nevertheless, curing conditions during baking of the EFB-coated substrates in the

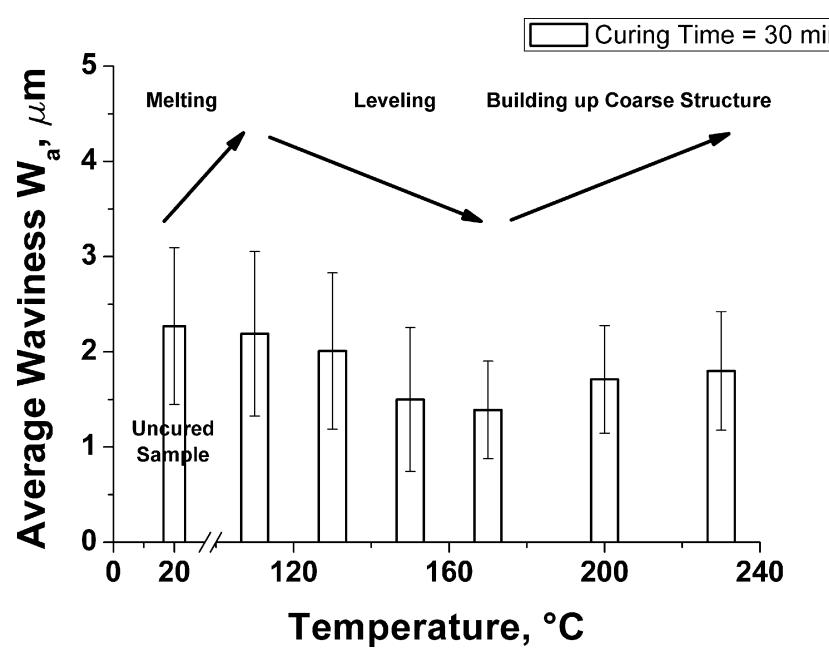

Fig. 7. Average waviness trend of the polymeric film for EFB-coated substrates according to curing temperature keeping curing time constant at $30 \mathrm{~min}$. 


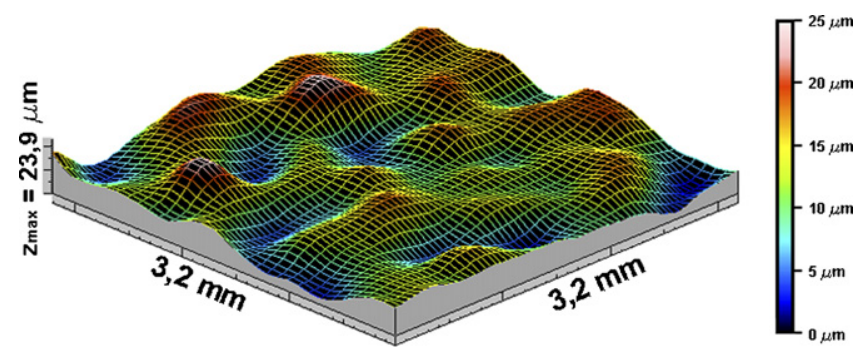

Fig. 8. Morphology of the uncured polymeric film deposited by EFB coating process.

convective oven and onto preheated metal substrates during CHDFB coating process are quite different. In fact, even if the same curing parameters (time and temperature) are set, different degrees of conversion between resin cured inside DSC and resin baked onto the metal substrate inside the convective oven in EFB coating process or cured onto preheated metal substrate in CHDFB coating process are expected. For such reason, the degree of conversion of the film onto the EFB- and CHDFB-coated substrates after curing process was estimated according to the procedure reported in Section 2.8 .

Tables 2 and 3 report the comparison between the degree of conversion calculated by using the kinetic model built in Section 3.1 and those experimentally achieved by estimating the residual heat of reaction of the polymeric films after cur-
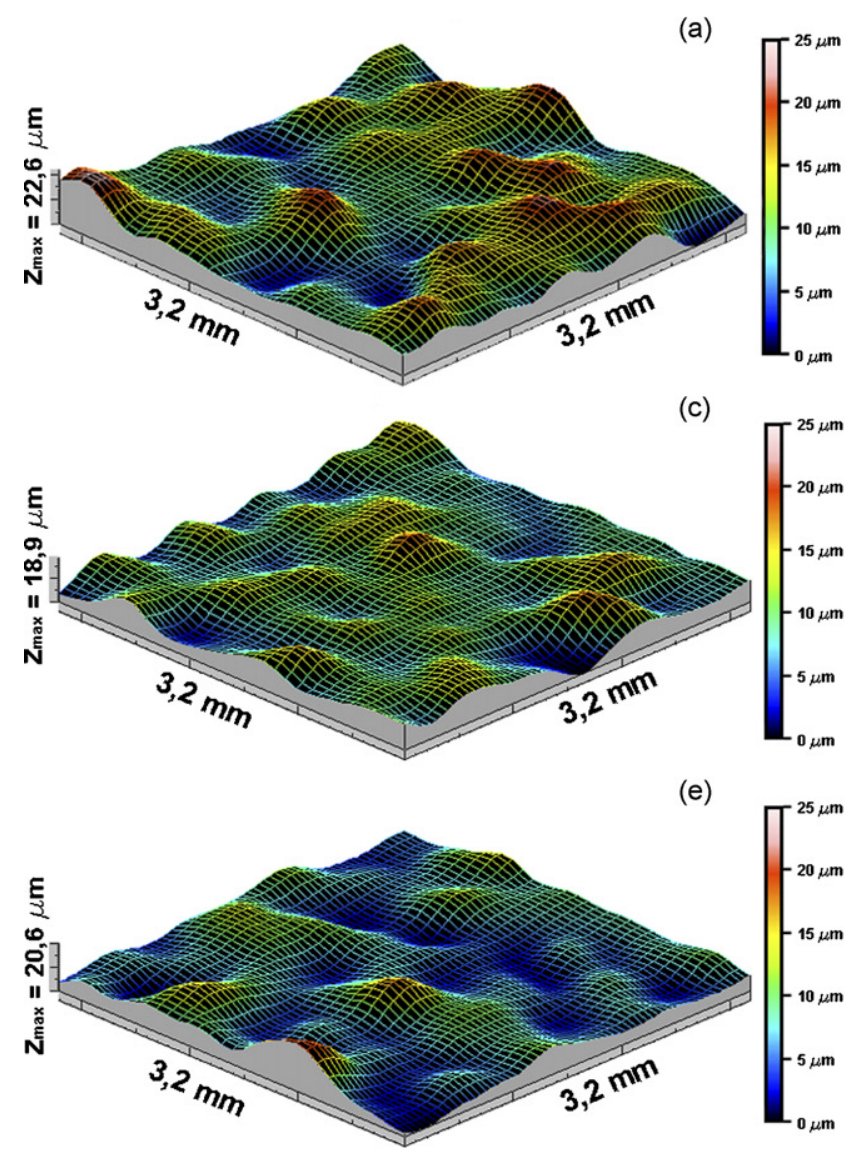

Table 2

DSC calculated degrees of conversion of the epoxy-based system according to curing time and temperature

\begin{tabular}{rllllll}
\hline$t(\min )$ & \multicolumn{2}{l}{$T\left({ }^{\circ} \mathrm{C}\right)$} & & & & \\
\cline { 2 - 6 } & 110 & 130 & 150 & 170 & 200 & 230 \\
\hline 1 & 0.016 & 0.047 & 0.122 & 0.257 & 0.509 & 0.700 \\
3 & 0.073 & 0.197 & 0.388 & 0.576 & 0.764 & 0.863 \\
5 & 0.143 & 0.331 & 0.539 & 0.698 & 0.836 & 0.905 \\
10 & 0.306 & 0.536 & 0.709 & 0.815 & 0.901 & 0.942 \\
15 & 0.426 & 0.642 & 0.781 & 0.862 & 0.926 & 0.956 \\
20 & 0.511 & 0.706 & 0.822 & 0.888 & 0.939 & 0.964 \\
30 & 0.622 & 0.779 & 0.867 & 0.916 & 0.954 & 0.973 \\
\hline
\end{tabular}

Table 3

Degrees of conversion of the epoxy-based system according to curing time and temperature evaluated onto EFB-coated substrates

\begin{tabular}{lllllll}
\hline$t(\min )$ & $T\left({ }^{\circ} \mathrm{C}\right)$ & & & & & \\
\cline { 2 - 6 } & 110 & 130 & 150 & 170 & 200 & 230 \\
\hline 1 & 0.008 & 0.023 & 0.061 & 0.136 & 0.309 & 0.501 \\
3 & 0.036 & 0.104 & 0.213 & 0.360 & 0.496 & 0.621 \\
5 & 0.073 & 0.182 & 0.336 & 0.445 & 0.597 & 0.720 \\
10 & 0.165 & 0.331 & 0.470 & 0.561 & 0.692 & 0.753 \\
15 & 0.247 & 0.406 & 0.534 & 0.617 & 0.728 & 0.766 \\
20 & 0.315 & 0.452 & 0.566 & 0.655 & 0.743 & 0.775 \\
30 & 0.391 & 0.525 & 0.622 & 0.709 & 0.764 & 0.793 \\
\hline
\end{tabular}
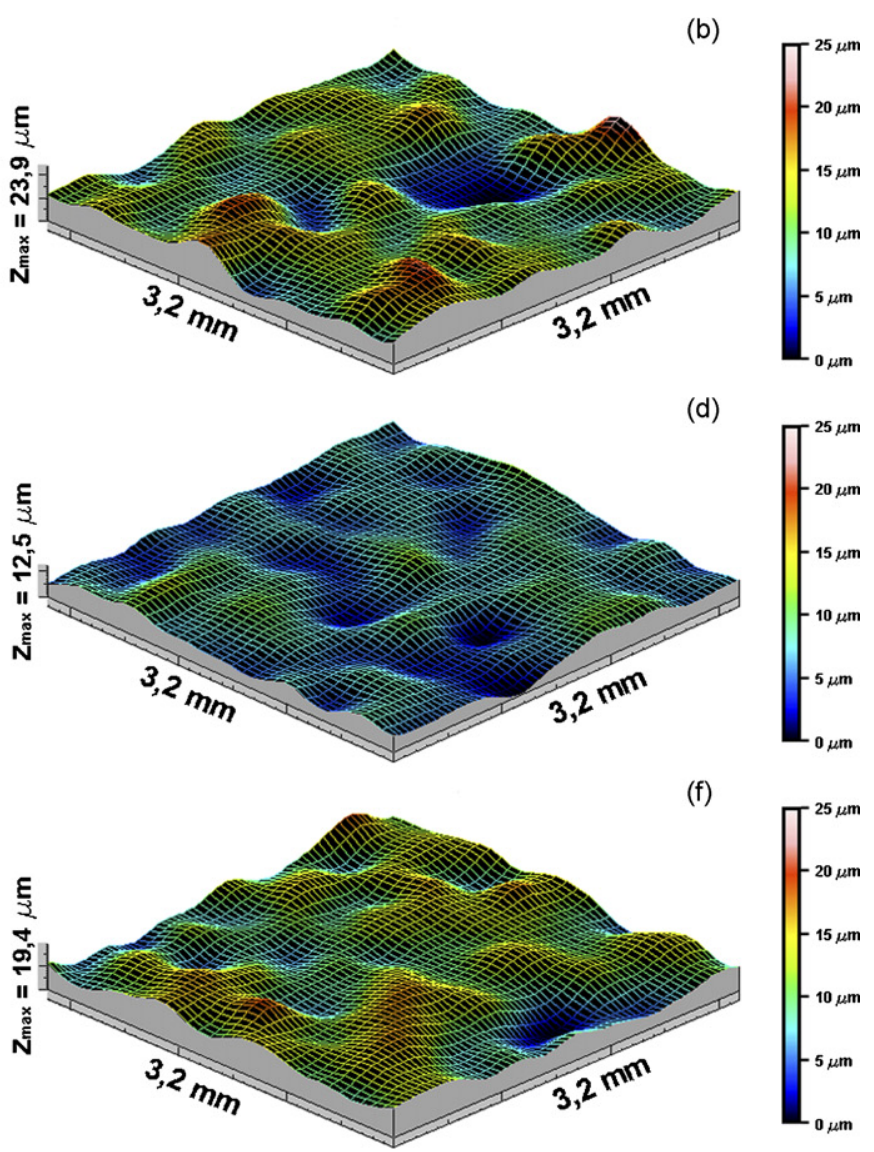

Fig. 9. Morphology of the polymeric film deposited by EFB coating process according to curing temperature keeping curing time constant at 30 min. 
Table 4

Degrees of conversion of the epoxy-based system according to preheating temperature evaluated onto CHDFB-coated substrates

\begin{tabular}{ll}
\hline Preheating temperature $\left({ }^{\circ} \mathrm{C}\right)$ & Degree of conversion \\
\hline 200 & 0.151 \\
250 & 0.395 \\
300 & 0.605 \\
350 & 0.812 \\
400 & 0.976 \\
\hline
\end{tabular}

ing in the convective oven for EFB coating process. It is worth noting that the resin cured inside the convective oven onto the EFB-coated metal substrates present quite lower values of degrees of conversion. These results can be ascribed to the thermal inertia typical of curing process in the convective oven, where quite big substrates and their coating should be simultaneously heated. For such reason, part of the heat provided by the oven is dispersed in heating the metal substrate and their surroundings, thereby determining a delay in activation of curing process of the polymeric film and, consequently, the lower values of the degrees of conversion. Nonetheless, such values are more realistic and truly representative of the resin status onto the EFB-coated metal substrates after curing process. Therefore, they will be considered in the next sections to analyse the interrelationship between surface appearance and thermorheological behaviour of the polymeric films in EFB coating process.

In CHDFB coating process, curing of deposited polymeric film is carried out onto preheated metal substrates, which progressively release their heat to cure the resin, while they lose their heat capacity becoming progressively cooler. With such a curing system, heating rate of resin cannot be monitored. It is just regulated by preheating temperature and it is too dependent by experimental procedure. Accordingly, the best way to attain the degree of conversion of the polymeric film coated by CHDFB is to apply the procedure reported in Section 2.8.

Table 4 reports the degrees of conversion of polymeric film onto metal substrate coated by $\mathrm{CHDFB}$ at different preheating temperatures (from 200 to $400^{\circ} \mathrm{C}$ ). As can be seen, at $200{ }^{\circ} \mathrm{C}$ as preheating temperature, the achieved degree of conversion was very low (around 0.15 ). Increasing temperature to $250{ }^{\circ} \mathrm{C}$, the degree of conversion approached to values very close to 0.4 and to gelation point of the resin. For temperature of $300{ }^{\circ} \mathrm{C}$ and higher, the degree of conversion of the resin rapidly approached values close to 1 and resin was well above its gelation point.

As expected, no direct comparison can be performed between results coming from kinetic models developed in Section 3.1 and the experimental results because of the peculiar curing process of polymeric film applied by CHDFB.

\subsection{Evolution of surface topography during curing onto EFB-coated substrates}

The surface structure build-up of the powder coatings was characterized using a surface topography system with a CLA-HE

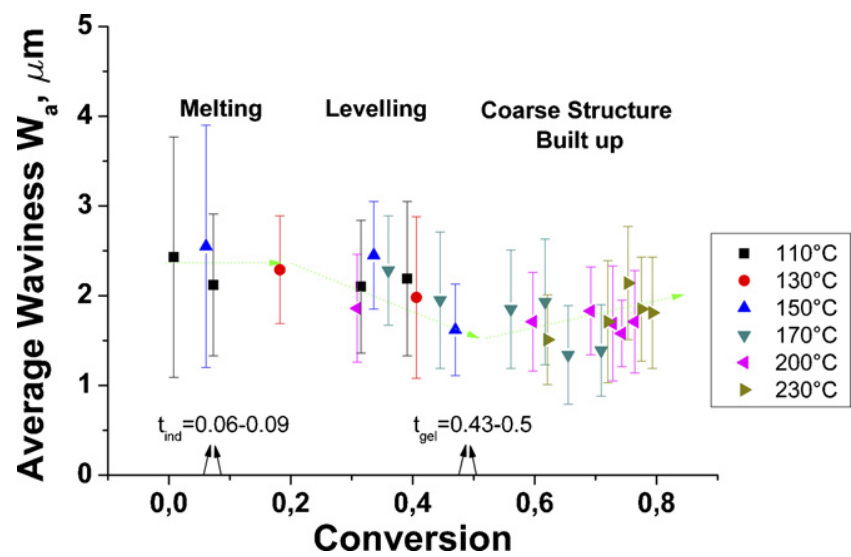

Fig. 10. Average waviness of the polymeric film deposited by EFB coating process according to degree of conversion. The influence of complex viscosity.

gauge. A FEG-SEM was also employed to observe the evolution of the surface morphology of the epoxy-based polymeric film during curing process.

The evolution of surface status of the polymeric films for EFB coating process is reported in Figs. 7-9 where the different phases through which the development of matte finishes has been

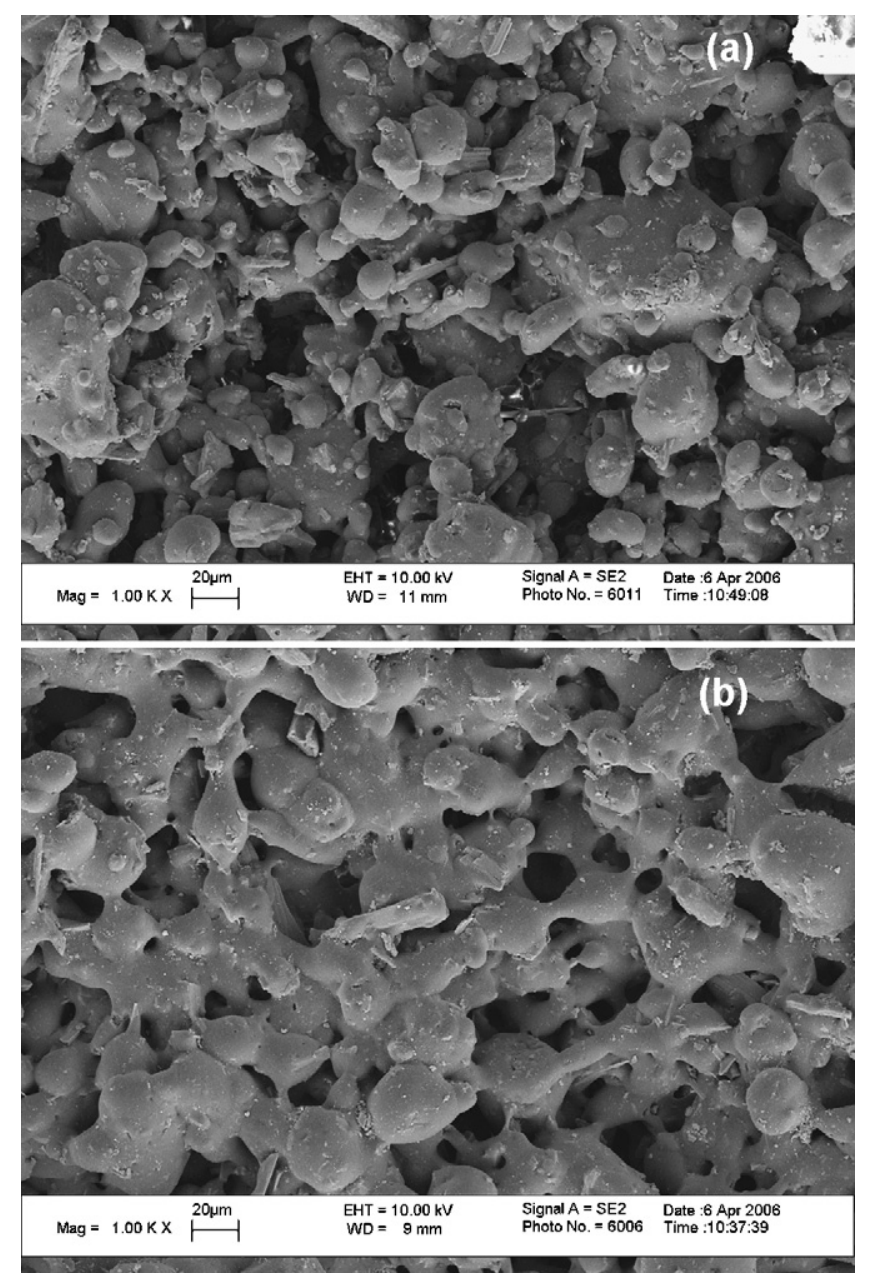

Fig. 11. SEM images of the polymeric film deposited by EFB coating process during the powder melting phase. 
established onto EFB-coated samples are fully depicted. The finishing level was first expressed in terms of average waviness of the measured profiles by varying curing temperature from 110 to $230^{\circ} \mathrm{C}$ and keeping curing time at $30 \mathrm{~min}$.

In EFB coating process, starting from the typical morphology of loose powders, the average waviness remained substantially unchanged for curing temperature of $110^{\circ} \mathrm{C}$ (melting). For curing temperature in the range of $130-170^{\circ} \mathrm{C}$, a significant decrease of the average waviness is observed (levelling). Average waviness went down from values around $2 \mu \mathrm{m}$ to more than $40 \%$ lower values (around 1.2-1.3 $\mu \mathrm{m}$ ). Further increase in curing temperature from 170 to $200^{\circ} \mathrm{C}$ and, finally, to $230^{\circ} \mathrm{C}$ was found to cause the average waviness go up from values around $1.2-1.3 \mu \mathrm{m}$ to values around $1.7-1.8 \mu \mathrm{m}$ (coarse structure build up). This last condition represents that typical of the fully cured film.
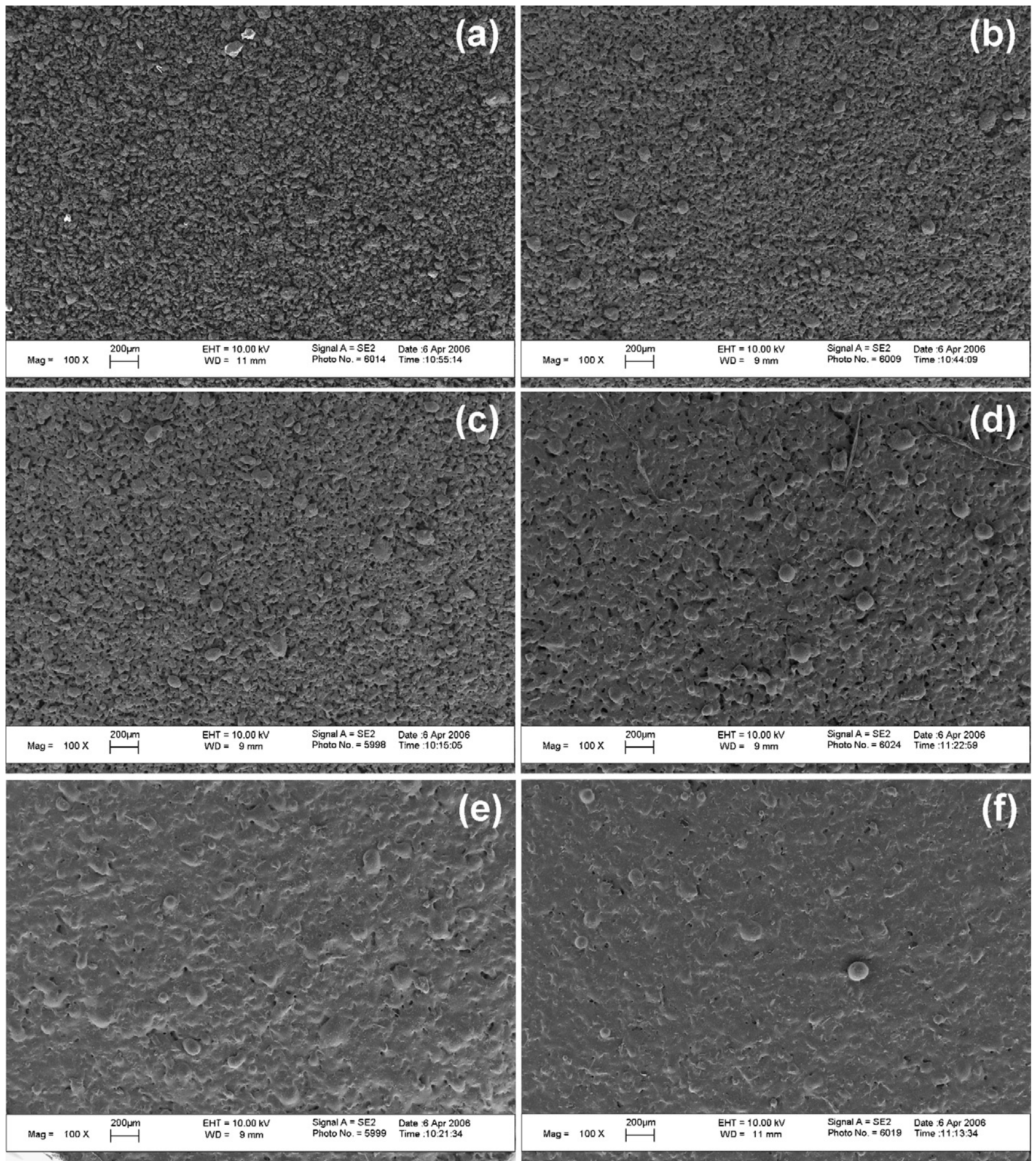

Fig. 12. SEM images of the polymeric film deposited by EFB coating process during the levelling phase. 
The overall morphology of the EFB-coated samples is thus submitted to three different transitions: the first one, from the status of loose powders (reported in Fig. 8, where the morphology of the uncured polymeric film can be seen) to the status of a just melted powders but still not consolidated in a form of a continuous film (panel a in Fig. 9, $110^{\circ} \mathrm{C}$ as curing temperature); the second one, from the status of just melted but still not consolidated powders to the status of smoothed film (panel d in Fig. $9,170^{\circ} \mathrm{C}$ as curing temperature) passing through several phases of increasing level of smoothing (panels $b$ and $c$ in Fig. 9,130 and $150^{\circ} \mathrm{C}$ as curing temperatures, respectively); the last one, from the status of smoothed films to the status of full development of the film matte finish (panel $\mathrm{f}$ in Fig. $9,230^{\circ} \mathrm{C}$ as curing temperature) passing through a status of incipient formation of the film matte finish (panel e in Fig. 9, $200^{\circ} \mathrm{C}$ as curing temperature).

In Fig. 10, to relate surface morphology of EFB-coated substrates and thermo-rheological behaviour of epoxy powders, the trend of waviness by varying the degree of conversion is reported. As can be seen, the trend is affected by high data variability due to the very rough surface morphology. Nevertheless, data variability went down for higher conversion values (smoother films), hence confirming reliability of experimental results and allowing a trustworthy correlation among morphological parameters, cure evolution and viscosity parameters. Therefore, at low conversion values (i.e. lower than 0.2), the melting of the powder occurred, with the waviness assuming values in the range of $2.2-2.6 \mu \mathrm{m}$. The first phase lasted until the dramatic increase in film viscosity (after the induction time $t_{\text {ind }}$ ) took place (see even Fig. 5). SEM images confirm such results. In fact, in Fig. 11 the transition, which occurred to the powders film during the first moment of the curing process, that is, during the melting phase, is displayed. As can be seen, from the status of loose powders, the film started to coalesce by build up of polymer necks among the different grains (necking phenomena). In particular, the powders started to lose the standard factor shape to progressively become rounder and rounder and form bonds with the surrounding powder grains (melting). At

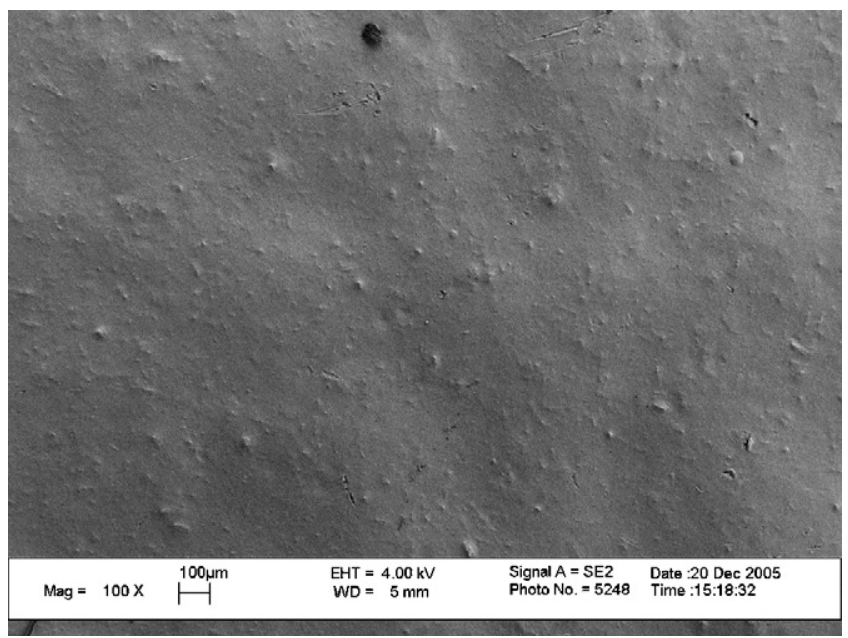

Fig. 13. SEM images of the polymeric film deposited by EFB coating process during the formation of the coarse structure.

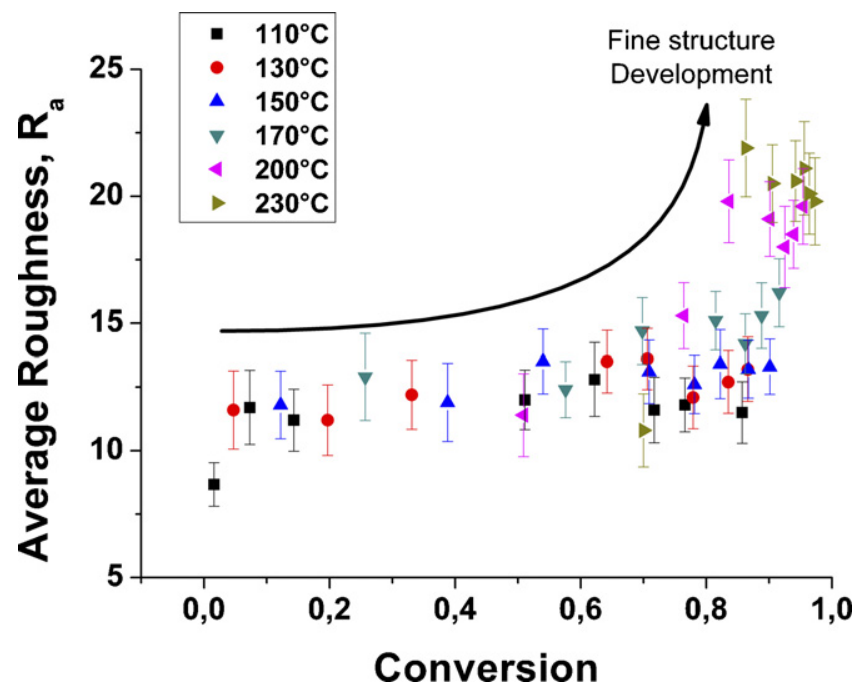

Fig. 14. Average roughness of the polymeric film deposited by EFB coating process according to degree of conversion. The influence of complex viscosity.

intermediate conversion values (i.e. from 0.2 to 0.5 ), the second phase characteristic of the curing process took place, that is, a significant decrease of waviness values from around $2.5 \mu \mathrm{m}$ to a little bit more than $1.5 \mu \mathrm{m}$ (Fig. 10). Accordingly, after the completion of the melting phase, a levelling of the powders film with a concurrent smoothing of the overall film morphology arose. The levelling phase lasted until the gelation of the polymeric film (i.e. until the gelation time $t_{\mathrm{gel}}$ ) took place, that is, until the resin viscosity approached to such a high value that further film levelling was prevented (see Fig. 5). The levelling phase can be much better appreciated if SEM images in Fig. 12 are considered. The photographs show the different levelling phases through which the samples surface went flat for intermediate values of curing temperature (from 130 to $170^{\circ} \mathrm{C}$ ). The film morphology passed through different scenarios: the full development of the necking phenomena and grains coalescence (Fig. 12 panels a and b); the progressive levelling of powder grains which totally lost their shape (Fig. 12 panels $\mathrm{c}$ and d); the full levelling of the polymeric film (Fig. 12 panels e and f), which became almost flat with no further grains being visible inside the compact and levelled poly-

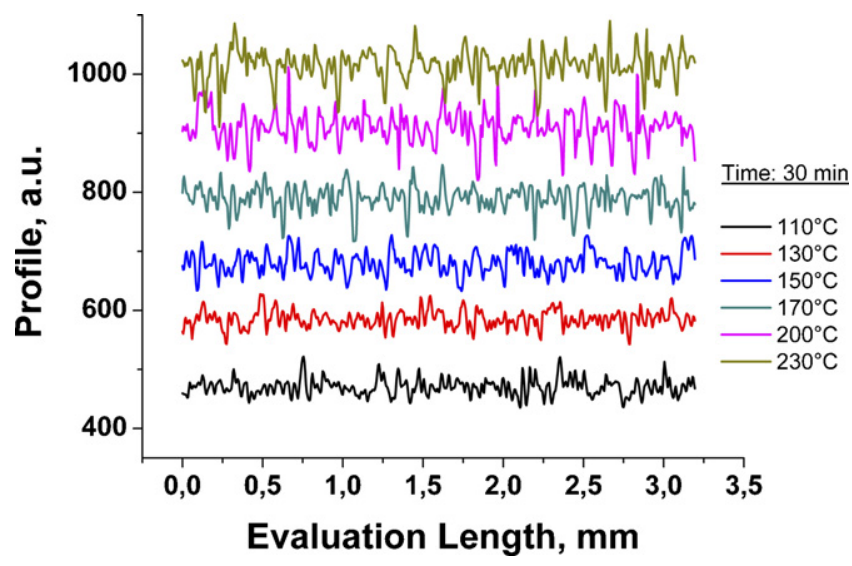

Fig. 15. Raw roughness profile of the polymeric film deposited by EFB coating process according to curing temperature. 


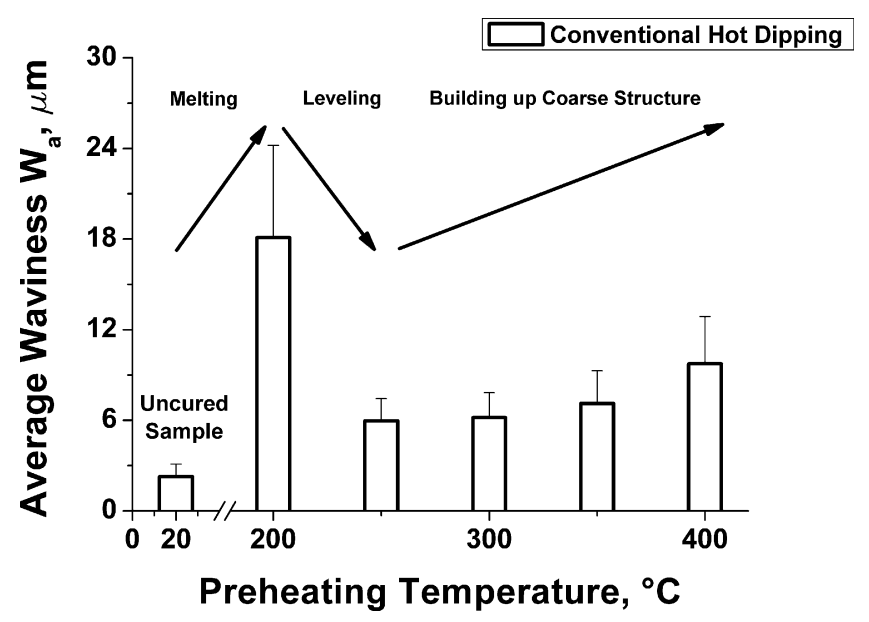

Fig. 16. Average waviness trend of the polymeric film for CHDFB-coated substrates according to preheating temperature.

meric film. At high values of conversion (i.e. higher than 0.5), the third and last phase characteristic of the curing process was detected. Average waviness increased from values a little bit more than $1.5 \mu \mathrm{m}$ to values around $2 \mu \mathrm{m}$ (Fig. 10). This result was associated to the built up of the film coarse structure. Such last phase developed after the gelation point of the polymeric film, that is, for viscosity values so high that flow capability of the polymeric chains are inhibited and only minor arrangements of the film morphology were still permitted. SEM image in Fig. 13 displays the sample morphology when a full development of the coarse structure has been established $\left(230^{\circ} \mathrm{C}\right.$ as curing temperature and $30 \mathrm{~min}$ as curing time), hence confirming the above experimental findings. As can be seen, a large-scale corrugation of the polymeric film took place after the completion of the curing process. This can be ascribed to the better flowing capability of the powders film when higher curing temperatures were employed. In fact, such temperatures allowed to attain very low minimum viscosity values during the first moment of curing process (i.e. before the resin viscosity approaches to the induction point), very helpful to film distension. Accordingly, on such spread films, full developments of film coarse structure took place.

The three different phases through which a powder layer became a continuous film was for the first time singled out by Lee et al. for epoxy-polyester and polyurethane systems [23]. Nonetheless, several differences arose between our and Lee's experimental results. In specific, Lee et al. highlighted the presence of a viscosity drop in epoxy system for curing values around $0.2-0.25$ and they ascribed the minimum of the average roughness (levelling phase) to the presence of such a viscosity drop [23]. In our analysis, the viscosity drop was not individuated. However, even in Lee's analysis such viscosity drop was clearly visible only at very low curing temperature (around $130^{\circ} \mathrm{C}$ ), when the resin gelation was very close (probably, too late to strongly influence final film morphologies).
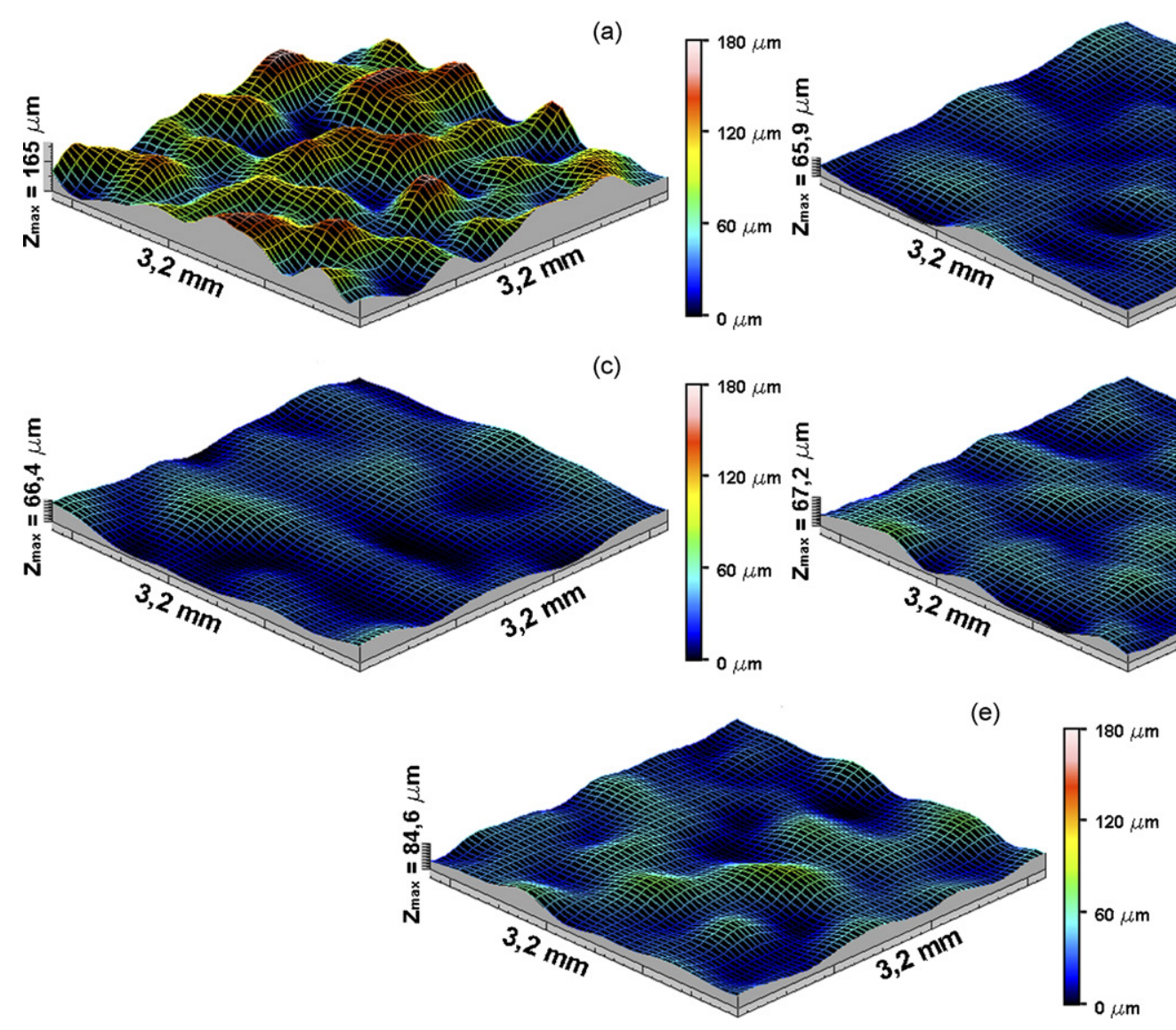

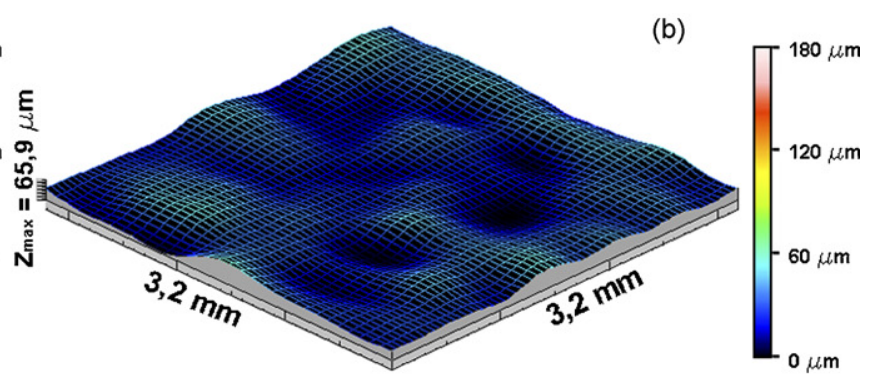

(d)

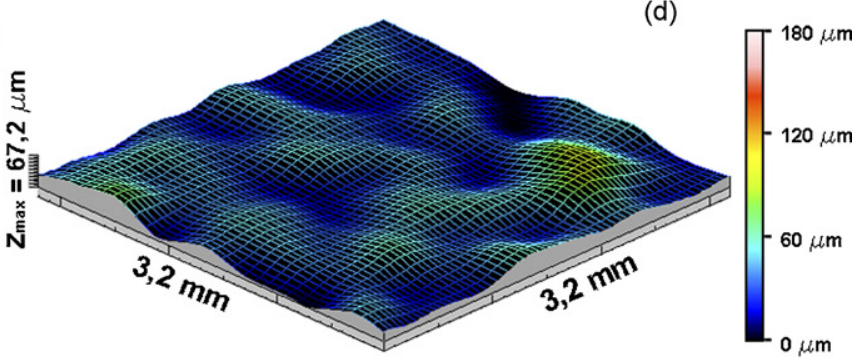

$\mu \mathrm{m}$ 
Fig. 14 reports the trend of average roughness according to conversion values for EFB-coated substrates. The average roughness values can be associated to the development of the polymeric films fine structure. As can be seen, the full development of the film fine structure arose only for very high conversion values (that is, higher than 0.7-0.8). A concurrent strong increase in average roughness was detected and fine structure became noticeable (Fig. 15). This means that the development of the fine structure followed the development of the coarse structure in epoxy-based systems. This result is in agreement with data reported in the literature, where for epoxy system the development of fine structure was always postponed to the built up of the coarse structure [23].

The late development of film fine structure can be probably ascribed to micro-scale rearrangement phenomena typical of polymer micro-structure during the final phases of curing process (conversion values close to 1) [26]. Therefore, going towards higher conversion values sharper profiles were superimposed on the almost standard coarse structure, hence determining significant variation of average roughness, which could vary even from values around $10 \mu \mathrm{m}$ up to values around $25 \mu \mathrm{m}$.

\subsection{Evolution of surface topography during curing onto CHDFB-coated substrates}

The surface status of the polymeric films for CHDFB coating process is reported in Fig. 16, where the different phases through which the development of matte finishes has been established onto CHDFB-coated samples are fully depicted. The finishing level was expressed in terms of average waviness of the measured profiles by varying substrate preheating temperature from 200 to $400{ }^{\circ} \mathrm{C}$.

In $\mathrm{CHDFB}$, the evolution of the average waviness can be described with the same phases of the EFB process. However, watching data reported in Fig. 16, a surprisingly high average waviness (around $18 \mu \mathrm{m}$ ) was found to characterize the surface topography of the sample preheated at $200{ }^{\circ} \mathrm{C}$. This was ascribed to the different curing process in $\mathrm{CHDFB}$, where the heat was

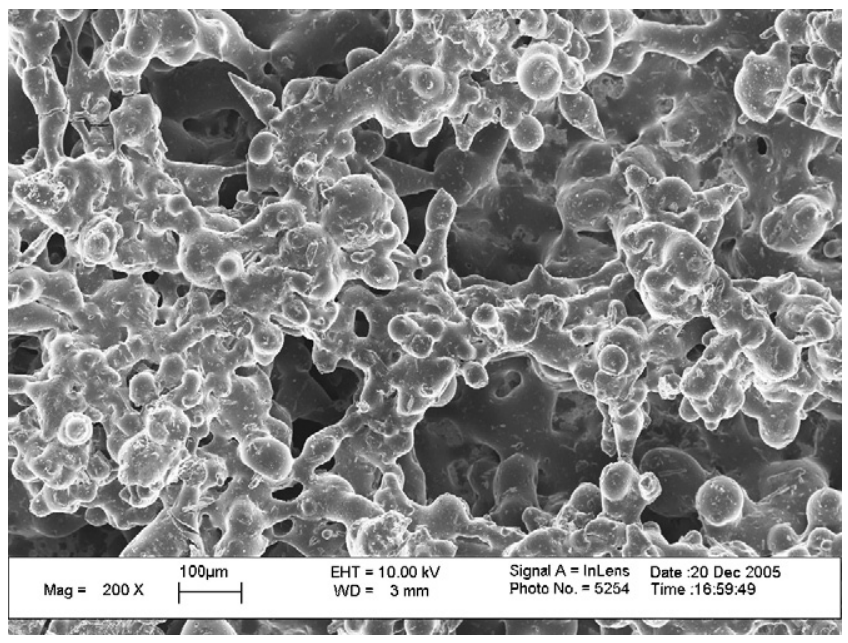

Fig. 18. SEM images of the polymeric film deposited by CHDFB coating process at $200^{\circ} \mathrm{C}$ as preheating temperature.

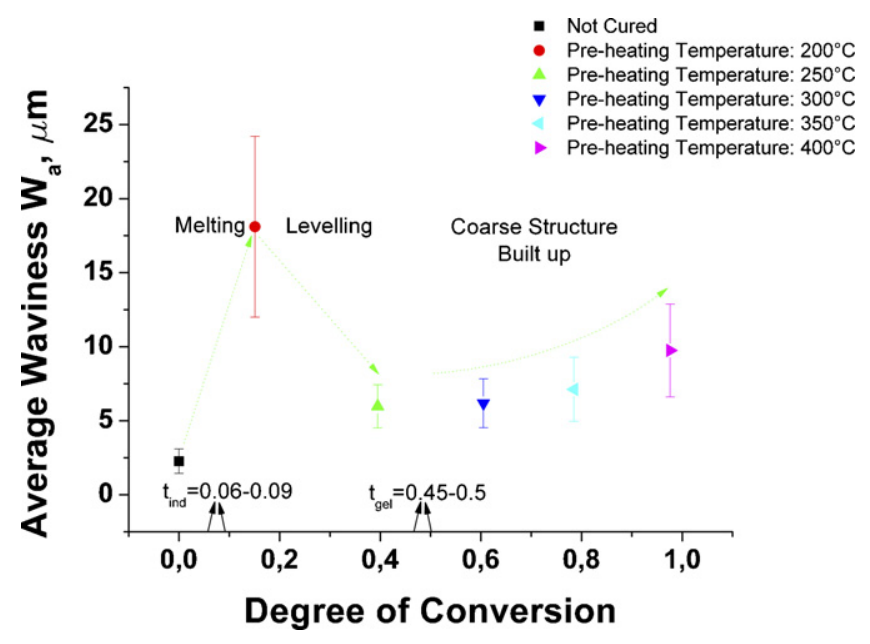

Fig. 19. Average waviness of the polymeric film deposited by CHDFB coating process according to degree of conversion. The influence of complex viscosity.

provided to the curing film from the bottom through the hot surface of the preheated substrate and not from the hot air as happens in the convective oven. This way, polymer cross-linking started from the bottom layers of the polymeric film, hence causing the swelling of the surface morphology. This occurrence can be probably ascribed to the strong degassing phenomena involved in curing process. Embedded air bubbles and some types of blocking agents employed to delay the cross-linking of the polymeric chains at low temperature remained trapped in the polymeric film during deposition [32], hence altering its overall morphology. Increasing temperature from 200 to $250{ }^{\circ} \mathrm{C}$, a substantial drop in average waviness (from 18 to about $6 \mu \mathrm{m}$ ) stood up as a result of the powders coalescence. Further increases in preheating temperature from 250 to $350{ }^{\circ} \mathrm{C}$, and, finally, to $400{ }^{\circ} \mathrm{C}$ were associated to a new increase in average roughness (up to values of 9-10 $\mu \mathrm{m}$ ) due to the built up of the film matte finish.

Fig. 17 shows the evolution of the surface morphology of the CHDFB-coated samples as monitored by CLA profilometry. As can be seen, even in CHDFB, the overall morphology of the examined samples was submitted to the three different

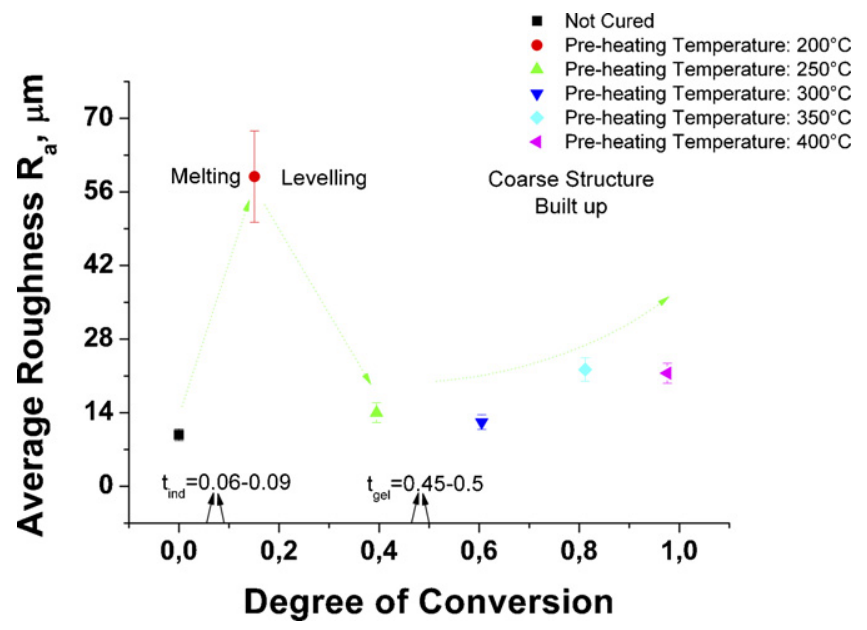

Fig. 20. Average roughness of the polymeric film deposited by CHDFB coating process according to degree of conversion. The influence of complex viscosity. 
transitions. The first one was observed at $200^{\circ} \mathrm{C}$ as preheating temperature (panel a in Fig. 17), where a corrugated surface topography developed (melting). SEM image of the sample morphology (Fig. 18) displays the partial melting of the polymeric powders and the characteristic large porosity due to the massive degassing phenomena. The second transition of the surface morphology of CHDFB-coated substrates was observed at $250^{\circ} \mathrm{C}$ (panel b in Fig. 17), where a substantial smoothing of the film morphology due to the powder coalescence and partial evacuation of the embedded gas bubble took place (levelling). The third transition was observed for temperature higher than $250{ }^{\circ} \mathrm{C}$ (panels c-e in Fig. 17), where the full development of the film coarse structure was displayed (build-up of coarse structure).

In Figs. 19 and 20, to relate the surface morphology of CHDFB-coated substrates and thermo-rheological behaviour of epoxy powders, the trends of waviness and roughness by vary-
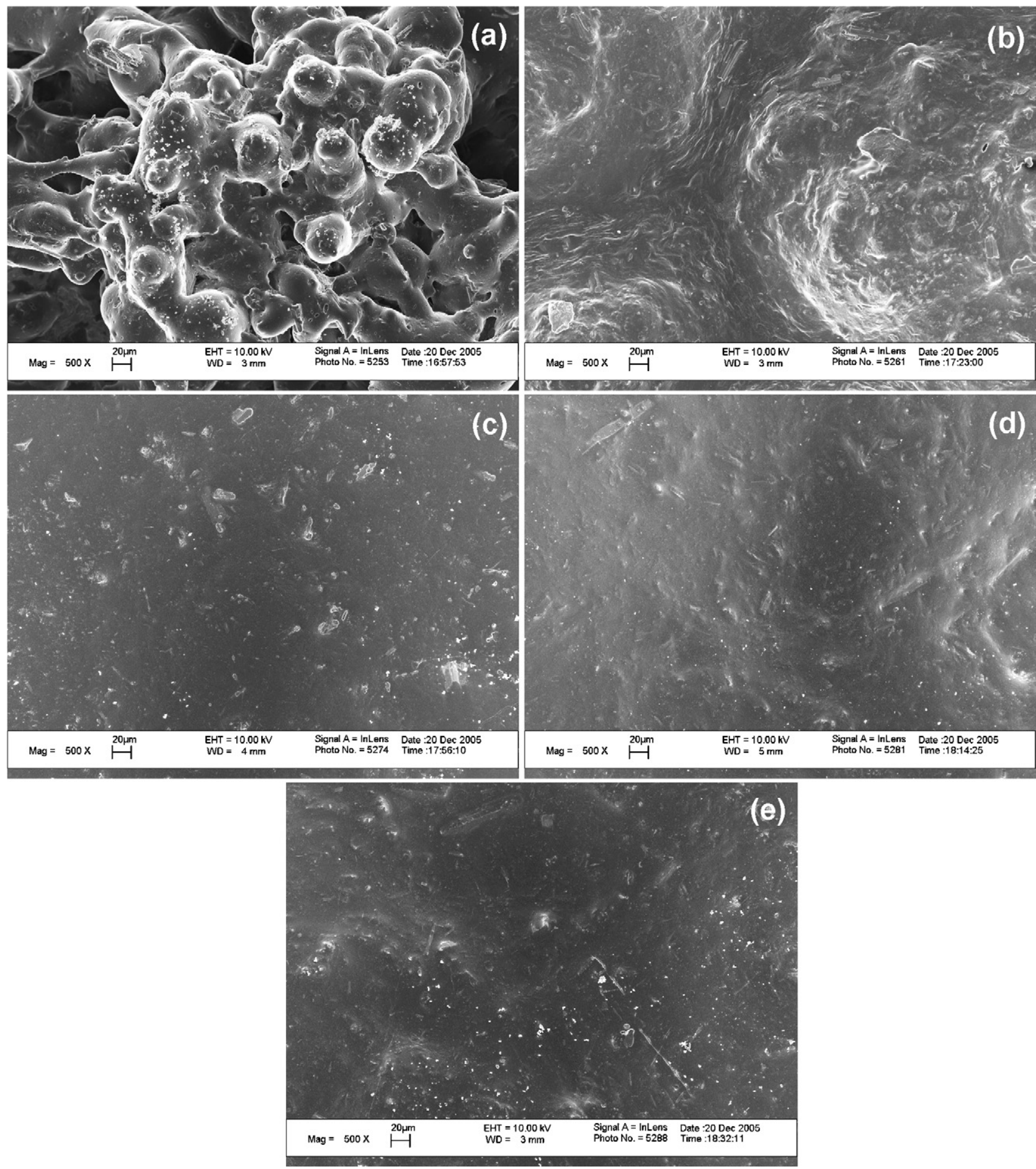

Fig. 21. SEM images of the polymeric film deposited by CHDFB coating process during the different phase of the evolution of the film morphology. Preheating temperature: (a) $200{ }^{\circ} \mathrm{C}$; (b) $250{ }^{\circ} \mathrm{C}$; (c) $300^{\circ} \mathrm{C}$; (d) $350{ }^{\circ} \mathrm{C}$; (e) $400^{\circ} \mathrm{C}$. 
ing the degree of conversion are reported. In particular, for the lowest preheating temperature of $200^{\circ} \mathrm{C}$ (i.e. conversion values around 0.15 ), the melting of the powder with a dramatic increase in waviness (assuming values in the range of 12-24 $\mu \mathrm{m}$ ) and roughness (assuming values in the range of 50-65 $\mu \mathrm{m}$ ) took place. Under such deposition conditions, the polymeric film underwent to a dramatic increase in viscosity (a degree of conversion around 0.15 corresponds to a resin viscosity well over the induction point). Such a viscosity increase blocked the film morphology in a highly uneven status, plenty of vacancies trapped inside the already consolidated polymeric film due, as previously said, to the embedding of gas bubbles. SEM images support such findings (Fig. 21 panel a). As can be seen, from the status of loose powders, the film started to coalesce by the build up of clearly visible polymer necks among the different grains (necking phenomena). Nonetheless, $200^{\circ} \mathrm{C}$ was a too low preheating temperature to permit a full liquefaction and distension of the polymer film. In fact, the metal substrate cooled down too quickly and its thermal capacity did not permit the establishment of the film full properties. As a result, film morphology remained highly corrugated. For preheating temperature of $250{ }^{\circ} \mathrm{C}$ (i.e. at intermediate conversion values around 0.4 ), a significant improvement of waviness and roughness to values around 6 and $16 \mu \mathrm{m}$, respectively, was detected (Figs. 19 and 20). Nonetheless, even $250{ }^{\circ} \mathrm{C}$ was a too low preheating temperature too permit the establishment of the full film
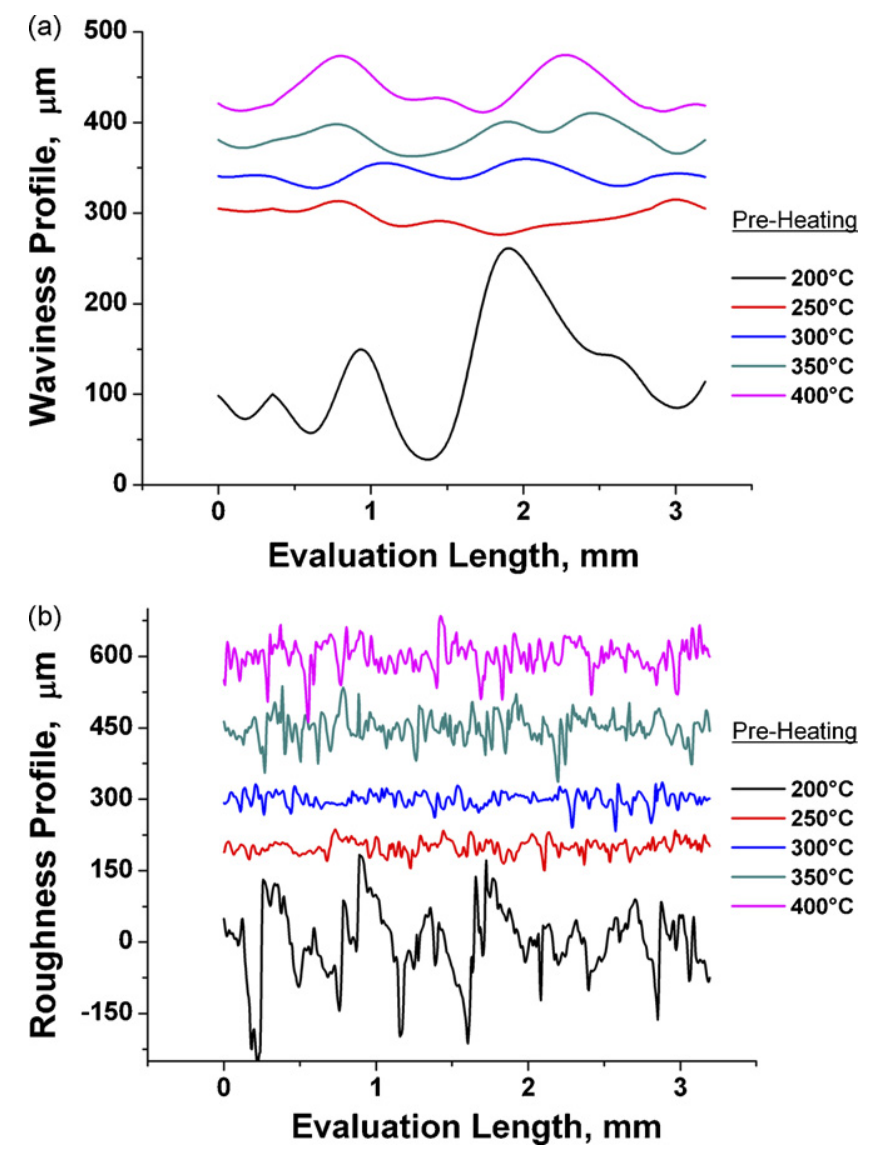

Fig. 22. (a) Raw roughness and (b) waviness profile of the polymeric film deposited by CHDFB coating process according to preheating temperature. morphology, which the epoxy-based systems were designed for. In fact, the metal substrate cooled down too quickly and viscosity of polymeric film approached values well over the induction point, but it did not approach the gelation point yet. Therefore, the input from the substrate was only sufficient to determine the full liquefaction of the film, without being able to provide enough heat to permit both the levelling and the development of the coarse structure (i.e. matte finish) onto the polymeric film. SEM images confirm such findings. Fig. 21 panel b shows the polymeric film levelling. The film morphology passed through the status of necking and grains coalescence (Fig. 21 panel a) to a status of progressive levelling of powder grains, which totally lost their shape (Fig. 21 panel b). Fig. 21 panel c shows the approach to a full levelling of the polymeric film, which became almost flat. This result was achieved for preheating temperature of metal substrate set at $300^{\circ} \mathrm{C}$, that is, for degree of conversion close to 0.6 and film viscosity just over the gelation point. At higher preheating temperature of the metal substrates (350 and $400^{\circ} \mathrm{C}$ ), that is, at degree of conversion around $0.8-1$, average waviness increased from values close to $6 \mu \mathrm{m}$ to values well above $10 \mu \mathrm{m}$ (Fig. 19) and average roughness increased from values a little bit more than $15 \mu \mathrm{m}$ to values well above $20 \mu \mathrm{m}$ (Fig. 20). These results were associated to the build up of the film coarse and fine structure. Such last phase developed well over the gelation point of the polymeric film, that is, for viscosity values so high that flow capability of the polymeric chains are inhibited and only minor arrangements of the film morphology were still permitted. SEM images in Fig. 21 panels $\mathrm{d}$ and e display the film morphology, when a full development of the coarse structure has been established, hence confirming the above experimental findings. As can be seen, a large-scale waviness of the polymeric film after the completion of the curing process took place.

The evolution of the surface morphology of CHDFB-coated substrates can be better understood if the raw waviness profiles according to preheating temperature are considered (Fig. 22 panel a). From the analysis of profiles shape, it is possible to note even more the three different phases which the polymeric films run through: the powder melting for $200{ }^{\circ} \mathrm{C}$ as preheating temperature, the film levelling for preheating temperature in the range of $250-300{ }^{\circ} \mathrm{C}$, the coarse structure build up for preheating temperature above $300^{\circ} \mathrm{C}$. The better development of film coarse structure for higher preheating temperature could be also associated to the lower minimum viscosity of the resin onto coated metal substrates induced by the larger amount of heat available during the first moment of the curing process (i.e. before the resin viscosity approaches to the induction point). This way, the resin got an improved flow capability onto the metal substrates when curing process starts, giving rise to a better film distension and, consequently, to a more favourable condition for the development of the film coarse structure.

Analogous considerations could be done if the evolution of the film fine structure reported in Fig. 22 panel $b$ is considered. As can be seen, the full development of fine structure took place for very high preheating temperature (above $300^{\circ} \mathrm{C}$ ) in agreement with results achieved for EFB-coated substrates. Even for CHDFB-coated substrates, this result is so attributable 
to micro-scale rearrangement phenomena typical of polymer micro-structure during the completion of curing process (conversion values close to 1) [26]. Therefore, going towards higher conversion values, sharper roughness profiles were superimposed on the almost standard coarse structure, hence determining significant increase in final average roughness values.

\section{Conclusions}

This study has provided advances in the understanding of the factors generating the surface structure, especially matte and wrinkled surfaces, of polymeric film in EFB and in $\mathrm{CHDFB}$ coating processes.

In particular, the most important experimental findings are reported hereafter:

- The surface structure build-up during curing was monitored with a combined SEM-CLA Profilometry. The evolution of film morphology during curing process is quite similar in both EFB and CHDFB coating process. It runs through three different phases: (i) powders melting, determined by a widespread necking phenomena between powder grains; (ii) powders levelling, determined by the completion of the melting process and by the full coalescence of the powder grains; (iii) formation of the film coarse and fine structure, ascribed to low and large-scale arrangements of the levelled films. However, remarkable differences between average waviness achievable by polymeric film in EFB (around $2 \mu \mathrm{m}$ ) and CHDFB (around $10 \mu \mathrm{m}$ ) coating processes arose as result of the different curing process.

- The isothermal complex viscosity and cure kinetic were studied systematically and the results could be related to the surface structure build-up in the epoxy-based systems for EFB- and CHDFB-coated substrates. In particular, (i) the powder melting stops just after the resin induction time elapses, that is, until a dramatic increase in resin viscosity occurs; (ii) the levelling phase lasts until the resin approaches to its gelation point. Afterwards, only minor rearrangements of the consolidated film are permitted, with no further flowing of the deposited material; (iii) the coarse surface structure is built up with the gelation point and continues to evolve after gelation. In EFB-coated samples, the fine surface structure develops after the full development of the coarse structure, hence causing significant changes of roughness value (up to $25 \mu \mathrm{m}$ ). In CHDFB, the development of fine and coarse structure took place almost simultaneously. Accordingly, average waviness and roughness present similar trends.

- The surface roughness and waviness were found to be strictly dependent on curing temperature. Increasing curing temperature means lower minimum viscosity values of the resin onto the coated substrates during the first moment of the curing process (i.e. before the resin viscosity approaches the induction point), faster completion of curing process, strong low and large-scale rearrangements of polymer micro-structure and, consequently, larger values of average roughness and waviness in both EFB- and CHDFB-coated substrates. Hence, general factors such as minimum viscosity and flow index may significantly affect the formation of the coarse and fine surface structure of the polymeric film.

\section{References}

[1] D.S. Richart, A report on the fluidized-bed coating system. Part 1. Fluidized bed variables and their influences, Plastics Des. Technol. 2 (1962) 18-26.

[2] D.S. Richart, A report on the fluidized-bed coating system. Part 2. Plastics for coating and their selection, Plastics Des. Technol. 2 (1962) 26-34.

[3] C.K. Pettigrew, Fluidized bed coating. Part 1. Effects of fluidized bed variables, substrate pretreatment and preheating method, Mod. Plastics 44 (1966) 111-117.

[4] C.K. Pettigrew, Fluidized bed coating. Part 2. Effects of dipping, postheating and complex geometrical variables, Mod. Plastics 44 (1966) 150-156.

[5] M.R. Strucaly, Electrostatic Powder Coating for Armature Impregnation, Electrostatic Technology Inc., Branford, Connecticut, USA, 1977.

[6] K.C. Leong, G.Q. Lu, V.A. Rudolph, Comparative study of the fluidizedbed coating of cylindrical metal surfaces with various thermoplastic polymer powders, J. Mater. Process. Technol. 89-90 (1999) 354-360.

[7] F.S. Ali, I.I. Inculet, Modelling of electric fields during electrostatic coating of metallic substrate in fluidized beds, IEEE Trans. Ind. Applic. 36 (5) (2000).

[8] F.S. Ali, I.I. Inculet, Electric field analysis of the tribocharged fluidized bed powder coating process, IEEE Trans. Ind. Applic. 36 (5) (2000).

[9] M. Barletta, V. Tagliaferri, Electrostatic fluidized bed deposition of a high performance polymeric powder on metallic substrates, Surf. Coat. Technol. 200 (14-15) (2006) 4282-4290.

[10] M. Barletta, V. Tagliaferri, Influence of process parameters in electrostatic fluidized bed coating, Surf. Coat. Technol. 200 (14-15) (2006) 4619-4629.

[11] M. Barletta, G. Simone, V. Tagliaferri, Advance in fluidized bed coating: an experimental investigation on a performance polymer coating alloy, J. Mater. Process. Technol. (2006).

[12] M. Barletta, G. Simone, V. Tagliaferri, A FEM model of conventional hot dipping coating process by using a fluidized bed, Prog. Org. Coat. 54 (4) (2005) 390-398.

[13] M.J. Hannon, D. Rhum, K.F. Wissbrum, J. Coat. Technol. 48 (1976) 42.

[14] K. Jensen, Paint Coat. Ind. 10 (1994) 58-64.

[15] D. Richart, Mod. Paint Coat. 12 (1995) 37-40.

[16] W.A. Purvis, S.F. Thames, J. Coat. Technol. 68 (1996) 67.

[17] A. Niroomand, T.P. Schuman, S.F. Thames, J. Coat. Technol. 68 (1996) 15.

[18] W. Jacobs, D. Foster, S. Sansur, R.G. Lees, Prog. Org. Coat. 29 (1996) 127.

[19] S.F. Thames, K.G. Panjnani, S.D. Pace, M.D. Blanton, B.R. Cumberland, J. Coat. Technol. 67 (1995) 39.

[20] S.G. Yeates, T. Annable, B.J. Denton, G. Ellis, R.M.D. Nasir, J. Coat. Technol. 68 (1996) 107.

[21] V.G. Nix, J.S. Dodge, J. Paint Technol. 45 (1973) 59.

[22] M. Barletta, A. Gisario, V. Tagliaferri, Electrostatic spray deposition (ESD) of polymeric powders on thermoplastic (PA66) substrate, Surf. Coat. Technol. 201 (1-2) (2006) 296-308.

[23] S.S. Lee, H.Z.Y. Han, J.G. Hilborn, J-A.E. Manson, Prog. Org. Coat. 36 (1999) 79-88.

[24] F. Reidenbach, ASM Metal Handbook Surface Cleaning, Finishing, and Coating, vol. 5, tenth ed., ASM International, Park, OH, USA, 1994.

[25] J.F. Richardson, Incipient fluidization and particulate systems, in: J.F. Davidson, D. Harrison (Eds.), Fluidization, Academic Press, New York, 1971.

[26] R.B. Prime, Thermal Characterization of Polymeric Materials, Academic Press, New York, 1981.

[27] M.R. Kamal, Polym. Eng. Sci. 14 (1974) 231.

[28] P.J. Halley, M.E. Mackay, Polym. Eng. Sci. 36 (1996) 593.

[29] D.W. Marquardt, J. Soc. Ind. Appl. Math. 11 (1963) 431.

[30] T. Nakamichi, Prog. Org. Coat. 8 (1980) 19.

[31] R.R. Eley, ACS Symp. Ser. 223 (1983) 281.

[32] K.D. Weiss, Prog. Polym. Sci. 22 (1997) 203-245. 